\title{
Limitations of the Neurological Evolutional Exam (ENE) as a motor assessment for first graders
}

\section{Limitações do Exame Neurológico Evolutivo (ENE) como um instrumento de avaliação motora para crianças da primeira série}

Priscila M. Caçola', Tatiana G. Bobbio², Amabile V. Arias², Vanda G. Gonçalves², Carl Gabbard'

\begin{abstract}
Background: Many clinicians and researchers in Brazil consider the Neurological Developmental Exam (NDE), a valid and reliable assessment for Brazilian school-aged children. However, since its inception, several tests have emerged that, according to some researchers, provide more in-depth evaluation of motor ability and go beyond the detection of general motor status (soft neurological signs). Objectives: To highlight the limitations of the NDE as a motor skill assessment for first graders. Methods: Thirty-five children were compared on seven selected items of the NDE, seven of the Bruininks-Oseretsky Test (BOT), and seven of the Visual-Motor Integration test (VMI). Participants received a "pass" or "fail" score for each item, as prescribed by the respective test manual. Results: Chi-square and ANOVA results indicated that the vast majority of children (74\%) passed the NDE items, whereas values for the other tests were $29 \%$ (BOT) and 20\% (VMI). Analysis of specific categories (e.g. visual, fine, and gross motor coordination) revealed a similar outcome. Conclusions: Our data suggest that while the NDE may be a valid and reliable test for the detection of general motor status, its use as a diagnostic/remedial tool for identifying motor ability is questionable. One of our recommendations is the consideration of a revised NDE in light of the current needs of clinicians and researchers.
\end{abstract}

Key words: motor skills; psychomotor performance; child development.

\section{Resumo}

Contextualização: Muitos clínicos e pesquisadores brasileiros consideram o Exame Neurológico Evolutivo (ENE), um instrumento válido e confiável para crianças brasileiras em idade escolar. Entretanto, desde a sua criação, surgiram outros testes para uma avaliação mais profunda de habilidade motora, os quais vão além de detectar status motor geral em forma de sinais neurológicos leves. Objetivos: Demonstrar os pontos fracos do ENE como teste de avaliação de habilidade motora para crianças de primeira série. Métodos: Trinta e cinco crianças realizaram 7 itens selecionados do ENE, 7 do teste Bruininks-Oseretsky (BOT) e 7 do Visual-Motor Integration Test (VMI), numa sessão única de 30 minutos. Para cada item, os participantes receberam a classificação "êxito" ou "fracasso", como prescrito por cada manual. Resultados: Os testes chi-quadrado e ANOVA indicaram que a vasta maioria das crianças (74\%) passaram nos itens do ENE, enquanto os valores para os outros testes foram 29\% (BOT) e 20\% (VMI). Análises das categorias específicas (fino, visual e motor grosso) revelaram um resultado similar. Conclusões: Estes dados sugerem que, enquanto o ENE pode ser um teste válido e confiável para detecção de status motor geral, a sua atuação como instrumento diagnóstico e de encaminhamento para identificação de habilidade motora é questionável. Uma das nossas recomendações é a consideração de uma versão do ENE revisada, baseada nas necessidades atuais de profissionais clínicos e pesquisadores.

Palavras-chave: habilidades motoras; performance psicomotora; desenvolvimento da criança.

Received: 19/02/2009 - Revised: 19/06/2009 - Accepted: 22/09/2009

${ }^{1}$ Department of Health and Kinesiology, Texas A\&M University, College Station, TX, USA

${ }^{2}$ Center for Investigation in Pediatrics (CIPED), Universidade de Campinas (UNICAMP), Campinas (SP), Brazil

Correspondence to: Priscila Caçola, Texas A\&M University, Department of Health and Kinesiology, 276A Read Building, TAMU 4243 - College Station, TX, USA 77843-4243,

e-mail: priscilacacola@hlkn.tamu.edu 


\section{Introduction : :}

Motor function assessments are useful to determine whether the child is developing normally or if there are delays requiring therapy and special assistance. Standards for motor assessments are often used as indicators for identifying developmental status and prescribing rehabilitative activities. Although there is a variety of acceptable motor performance assessments for use with infants and preschoolers, there are only a few assessments for school-age children (six years and older). The importance of this fact was underscored by Bessa and Ferreira ${ }^{1}$ when they suggested that an adequate motor coordination assessment is essential for school-age children, as any alteration in this capacity may interfere with school learning and general behavior.

Among the most common tests used internationally are (a) the Bruininks-Oseretsky Test (BOT)2 for ages five to 14 years, (b) the Visual-Motor Integration Test (VMI) ${ }^{3}$ for ages three to seven years, (c) the Peabody Developmental Motor Scales (PDMS-2) ${ }^{4}$ for ages zero to seven years, (d) the Test of Gross

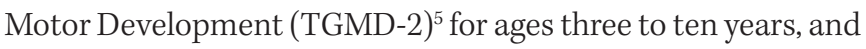
(e) the Movement $\mathrm{ABC}(\mathrm{M}-\mathrm{ABC})^{6}$ for ages three to 16 years. In our search for a motor assessment for school-age children in Brazil, one of the most widely used and highly recommended was the Neurological Developmental Exam ${ }^{7}$ (NDE), designed for children aged three to seven years. The instrument has been recognized for its ease of administration and strong set of standards for Brazilian children.

The NDE was developed to facilitate the administration of neurological assessment in clinical examinations. The exam consists of 124 test items that assess the functional development of the nervous system. The test items are divided into blocks to assess speech, static balance, dynamic balance, fine motor coordination, upper-body coordination, motor persistence, muscle tonus and sensibility. The test is administered individually, and the scoring system is relatively simple: each item is scored as "pass" when the child is able to perform the task or "fail" when the child is unable to execute the task appropriately. The NDE has been reported as a valid and reliable assessment with Brazilian children ${ }^{8-12}$.

Bobbio et al. ${ }^{13}$ recently evaluated 402 first graders using the NDE and found an unusually high passing rate for virtually all test items. In addition, a 'ceiling effect' was observed. With the exception of a few gross motor items identified as interlimb coordination skills, $85 \%$ or more passed in the categories of visual, fine, and gross motor coordination at the end of the school year. In essence, the test items were too easy for the vast majority of children. When designing the present study, the researchers asked four international experts in motor assessment for their opinion on task item classification. Interestingly, their evaluation concluded that, in general, the NDE was an assessment of "soft neurological signs" (SNS), i.e. the test can be used to detect "general motor [neurological] status and minor abnormalities", which is in accordance with the NDE's purpose.

Nevertheless, and relevant to the aim of this paper, it has been suggested that SNS tests such as the NDE are not sensitive enough to assess motor ability or detect specific motor development delays, especially the ones related to daily life skills. It is important to note that it is not uncommon for researchers and clinicians to use the NDE to identify motor ability, motor delay, and prescribe remediation, which arguably is not the purpose of the NDE. In fact, Vohr ${ }^{14}$ pointed out that assessments that are basically neurological are poor predictors of motor delays. Furthermore, the NDE was created in 1979, and since then it has not been revised.

In order to demonstrate the limitations of the NDE, compared to more contemporary assessments of wide use, we compared motor scores of children evaluated with selected items of the NDE with selected items from two internationally used motor assessment batteries that have reputable psychometric properties, namely the $\mathrm{VMI}^{15}$ and the $\mathrm{BOT}^{16}$. Test selection was based primarily on test availability and appropriateness for the age group tested. We hypothesized that significantly more children would achieve passing scores with the NDE. This result would add to our initial expectation that, compared to more contemporary tests, the NDE is less sensitive in detecting motor skill delays.

\section{Methods :::}

\section{Participants}

The study involved a convenience sample of 35 first graders (20 males, 15 females) from Campinas, a large city in southeast Brazil. Participants were recruited from a single public school. At this particular school, class size was approximately 40 students, physical education was provided twice a week, and art classes once a week. Children were excluded from the study if they had previously failed the first grade, did not attend school regularly, required special care, did not wish to be evaluated, and had physical, mental or neurological disorders. The mean age was 6.8 years $( \pm 0.37$; range 6.7-7.3 years). Considering the gender division, the mean age for females was $6.7( \pm 0.9)$ and for males, $6.7( \pm 0.6)$, showing no statistical difference for gender and age $(p=0.11)$. All participants were volunteers via agreement with the children and parent or guardian. This research project was approved by the Research Ethics Committee of the School of Medical Sciences, Universidade Estadual de Campinas (UNICAMP), Campinas (SP), Brazil, under protocol number 818/2008. 


\section{Assessment of motor function}

All 35 children were submitted to selected test items of the $\mathrm{NDE}, \mathrm{VMI}$ and BOT. It is important to mention that, to the best of our knowledge, the VMI and BOT have not been validated for use with the Brazilian population. However, our goal was to use them only as comparative measures for the NDE. Hence, two Brazilian researchers translated the two test items into Portuguese. The selected items for each test used are shown in Table 1.

We used seven items from the original "upper body (appendicular) coordination" section of the NDE. Within that section, we identified tasks that could be grouped as visual-motor integration (2), fine motor control (1), and gross motor coordination (4). More specifically, these items were evaluated as tasks requiring interlimb coordination. It is important to note that classifications were based on the expert opinion of four motor assessment specialists from the USA.

For the VMI, we chose seven items that assess integration between visual and motor abilities. For the BOT, we chose seven items representing interlimb coordination (6) and visualmotor control (1). It is worth noting that although the items were obviously not identical across tests, the group of tasks represented the specific test's assessment of motor ability for that category.

The instructions for each item, as defined in the manuals, were rigorously followed. A single examiner trained to administer and report on all tests conducted the assessments in an isolated room. All children performed the three tests in a single session (lasting approximately 30 minutes) in the following order: NDE, VMI, and BOT. The BOT and NDE tasks were first demonstrated by the examiner, and the child then had two chances to perform each task. For the VMI, geometric figures were shown, and the child was asked to copy them, as instructed in the manual. The item was scored as "fail" if the child was unable to achieve the objective of the task or as "pass" if the child performed the task correctly, as prescribed by the respective test manual. For the few items that belonged to two tests simultaneously (i.e. NDE and BOT), we used the respective scoring system for that test to define the score. In addition, BOT items 2 and 7 presented a "point score" instead of "pass" or "fail", therefore we simply assigned a passing score to the child who achieved $50 \%$ or more of the point score and a failing score otherwise.

Table 1. Selected items from the NDE, BOT, VMI and categories.

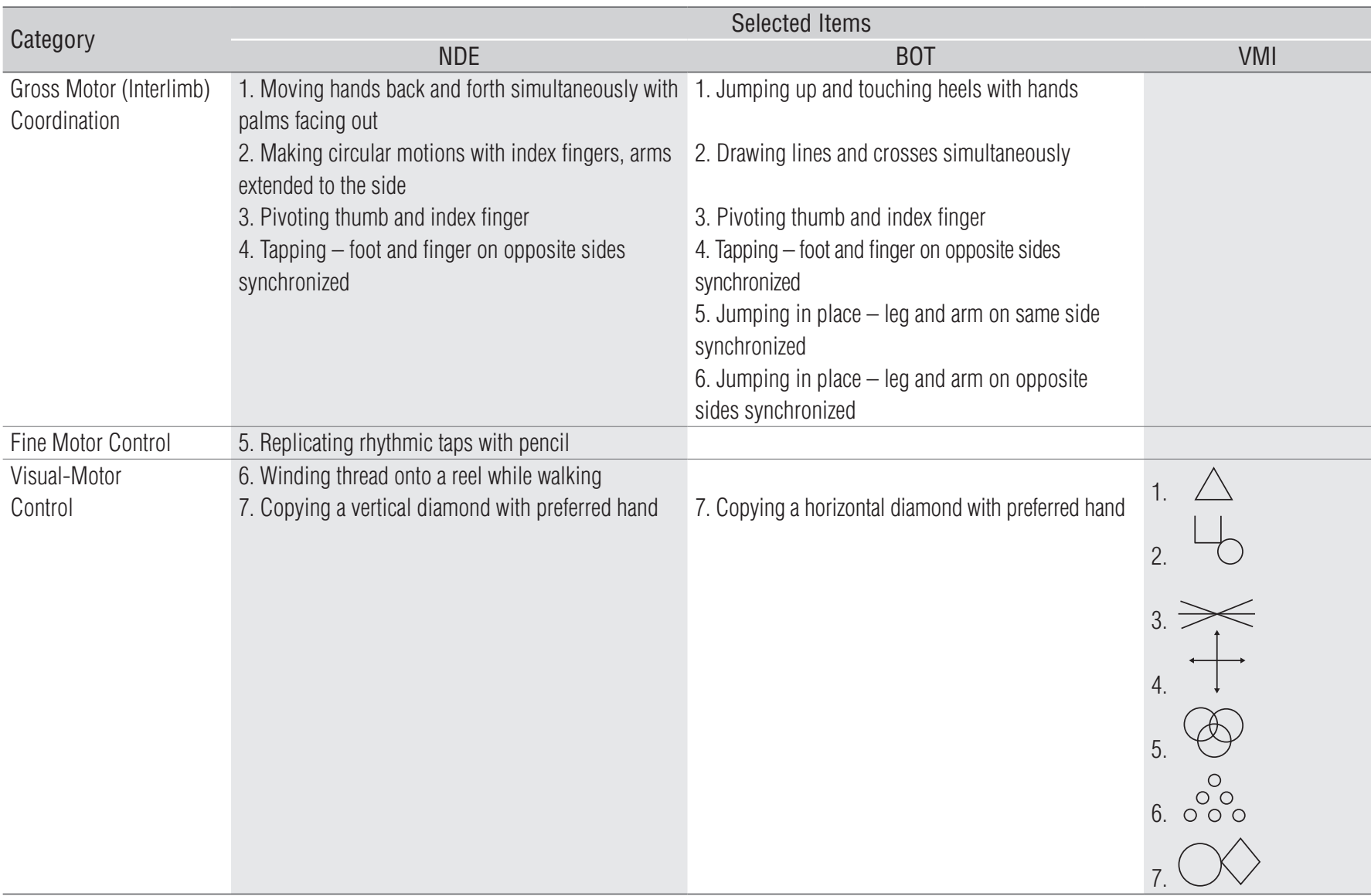

${ }^{*}$ For all VMI items, the task was simply to copy the geometric figures with the preferred hand (figures are not displayed in real size). 


\section{Treatment of the data}

Data (scores) were analyzed using frequency analyses and chi-square procedures to compare participants classified as "pass" or "fail". Analyses were performed with Epi-Info 6.0 and SPSS 15.0. Statistical significance was set at $\mathrm{p}<0.05$.

\section{Results $: \because$.}

The percentages of participants who passed each test (composite score for all sections) were $29 \%$ for the BOT test, $74 \%$ for the NDE test and 20\% for the VMI test. Chi-square analysis revealed significant differences between the tests $\left(X^{2}(2)=24.6\right.$; $\mathrm{p}<0.0001)$. As shown in Table 2, scores were lowest on the BOT and VMI tests, and highest on the NDE test. According to these results, $71 \%$ of participants failed when evaluated with the BOT items, and $80 \%$ with the VMI.

\section{Discussion $: \because$.}

The purpose of the present study was to highlight the limitations of the NDE. In order to do that, we compared the participants' scores for selected items of the NDE with their scores for two other motor assessment batteries that are recognized for providing more in-depth evaluation of motor ability, i.e. the $\mathrm{VMI}^{15}$ and BOT ${ }^{16}$. As hypothesized, significantly more children obtained passing scores for the NDE than for the BOT and VMI assessments, and data for the BOT and VMI were similar. In both tests, more than $70 \%$ of the participants were classified as "fail".

The present findings address interesting observations. First, we found that the NDE assessment is indeed a less sensitive test of motor skills compared to the VMI and BOT. The vast majority of children in our sample passed almost all of the NDE items, confirming the unusually high passing rate found by Bobbio et al. ${ }^{13}$. This is in contrast to having failed the majority of items from the other tests we selected. This result means that in a clinical assessment, for instance, more than $50 \%$ of the children in our study would be identified as "typically developing" when evaluated with the NDE. Arguably, this finding supports the suggested fragility of the NDE for specific motor functions, especially those items related to daily life skills. This is not a surprising fact, as the intended purpose of the NDE was not to test motor skills. Nevertheless, this test has been widely used to determine levels of motor behavior for clinical assessment and research purposes (for examples, see references 9 and 10).

We wish to note that our purpose was not to compare domains between tests but rather compare age-related test items in general. However, interesting points are worthy of note. For example, out of seven selected items of the NDE, two represented visual-motor integration, one represented fine motor coordination, and four were defined as interlimb coordination (with the gross motor section). For the VMI, we chose seven items that assessed integration between visual and motor abilities, and for the BOT, six items were selected from the sections of interlimb coordination and one from visual-motor control. In our sample, the visual-motor component of the VMI was the section in which the participants had the poorest performance, with a $20 \%$ passing rate. The VMI assessment requires the child to copy a series of geometric designs. According to Goyen and Duff ${ }^{17}$, visual-motor integration may be more important when children are learning to form letters, when speed is not important, and reliance on visual feedback may be greater. Our sample of children was finishing the first grade of elementary school when they were administered the tests, and it is quite puzzling that only a small portion of them (20\%) were able to pass the skills required by the VMI. We would have expected at least $50 \%$ of the group would pass the visual-motor integration items; the literature supports the notion that this characteristic plays an influential role in the primary stages of learning letter formation ${ }^{17}$. However, for such a generalization, we admit that our relatively small sample size may have been a factor.

Only the NDE and the BOT assessments provide specific tasks of interlimb coordination, and as expected, scores for the latter were lower than those for the former. It is important to note that the interlimb coordination items from the NDE were actually listed in the gross motor section. Interlimb coordination involves the timing of locomotor cycles of the limbs in relation to one another ${ }^{18}$. In the context used here, that meant alternating opening and closing hands, alternating tapping finger/foot of one side with the other side, turning hands simultaneously with arms extended, and matching a rhythm with alternating feet tapping. Although basic characteristics of interlimb coordination are displayed by the end of the first year, it appears considerable improvement occurs from about age six to ten years ${ }^{18-21}$.

In regard to the implications of the present study, our findings have local as well as possibly far-reaching implications. First, however, we feel the need to mention the strengths of the NDE. In Brazil, the NDE is recognized by many as a relatively

Table 2. Percentage of children identified as "pass" and "fail".

\begin{tabular}{lrrr}
\hline Tests & Fail & Pass & \multirow{2}{*}{$\chi^{2}$} \\
& N (\%) & N (\%) & \\
\hline BOT & $25(71.4)$ & $10(28.6)$ & \\
\hline NDE & $9(25.7)$ & $26(74.3)$ & $24.6^{*}$ \\
\hline VMl & $28(80.0)$ & $7(20.0)$ & \\
\hline
\end{tabular}

${ }^{*} \mathrm{P}<0.001$ 
easy-to-administer, valid, and reliable test of SNS in children, even though it was created three decades ago. In addition, it has a large set of standards based on Brazilian children.

However, the NDE could have limitations as a research tool, and according to our findings, it was less sensitive in detecting motor ability. If we were to re-evaluate the NDE, we would suggest that researchers and clinicians take a close look at the potential considerations addressed by the present study. First of all, NDE scores presented a "ceiling effect" for 7-year-old children. Bobbio et al..$^{22}$ found that $85 \%$ of children in a large sample obtained passing scores with the NDE. In addition, the age range for NDE is limited: three to seven years. Moreover, if the aim is to gather specific information regarding the developmental status of the child, perhaps other motor tasks should be added to the NDE assessment. Also, gross motor and interlimb coordination as well as fine motor coordination and visual motor integration sections should be separated.

Some points warrant mention when it comes to the limitations of the present study. Once again, the sample was relatively small and restricted to one city, which obviously limits the generalization of results. In addition, the VMI and BOT test items were translated into Portuguese for the purposes of this study; however, they were not submitted to transcultural adaptation.
Our goal was to use those tests for comparative purposes only. Obviously the tests in their entirety are not comparable, but we feel that their role as illustrative measures was fulfilled. Given that these international tests have not yet been validated for Brazilian children does not, in our opinion, take away from the suggestion to revise the NDE and perhaps reconsider its use. One of the merits of our findings is that they could be used to revise and amplify the scope of the NDE. Tests such as the VMI and BOT present items that could be included in a revision of the NDE and/or the creation of another instrument that taps more characteristics of motor skill development for Brazilian children.

And finally, we wish to point out that we acknowledge that no single assessment instrument tests all facets of motor function. Therefore, researchers and practitioners need to determine what their goals are (testing specific motor delays or general neurological status) and select the appropriate test or combination of tests. Here, we demonstrated some possible limitations of the NDE as an assessment of motor skills and provided suggestions for strengthening the instrument. And, finally, it is our strong belief that the NDE, with adequate revision, could continue to be an effective tool for assessing schoolage Brazilian children.

\section{References}

1. Bessa MFS, Ferreira JS. Balance and motor coordination in preschool: A comparative study. Rev Bras Ciênc Mov. 2002;10(4):57-62.

2. Bruininks RH. Bruininks-oseretsky test of motor proficiency. Minnesota: Circle Pines; 1995.

3. Beery KE. Developmental test of visual-motor integration. $4^{\mathrm{a}}$ ed. New Jersey: Modern Curriculum Press; 1997.

4. Folio MR, Fewell RR. Peabody developmental motor scales. $2^{\mathrm{a}}$ ed. Austin: PRO-ED; 2000

5. Ulrich DA. Test of gross motor development (TGMD-2). $2^{\mathrm{a}}$ ed. Austin: PRO-ED; 2000.

6. Henderson SE, Sugden DA. Movement assessment battery for children (Movement ABC). $2^{\mathrm{a}}$ ed. London: Psychological Corporation; 2007.

7. Lefévre AB. Exame neurológico evolutivo. São Paulo: Savier; 1979

8. Galante GA, Azevedo CSA, Mello M, Tanaka C, D'Amico EA. Evaluation of postural alignment and performance in functional activities among hemophilic children under 7 years-old with and without chronic synovitis: correlation with hemarthrosis incidence. Rev Bras Fisioter. 2006;10(2):171-6.

9. Possa MA, Spanemberg L, Guardiola A. Attention-deficit hyperactivity disorder comorbidity in a school sample of children. Arq Neuropsiquiatr. 2005;63(2B):479-83.

10. Navarro AS, Fukujima MM, Fontes SV, Matas SL, Prado GF. Balance and motor coordination are not fully developed in 7-year-old blind children. Arq Neuropsiquiatr. 2004;62(3A):654-7.

11. Guardiola A, Fuchs FD, Rotta NT. Prevalence of attention-deficit hyperactivity disorders in students. Comparison between DSM-IV and neuropsychological criteria. Arq Neuropsiquiatr. 2000;58(2):401-7.

12. Guardiola A, Ferreira LT, Rotta NT. Performance of literacy and cortical brain functions in a sample of first grade students of Porto Alegre, Brazil. Arq Neuropsiquiatr. 1998;56(2):281-8.
13. Bobbio TG, Gabbard C, Gonçalves VMG, Barros Filho AA, Morcillo AM. Interlimb coordination differentiates Brazilian children from two socioeconomic settings. Pediatr Int. 2010; 52:353-7.

14. Vohr BR. Progress in predicting outcomes for extremely low birth weight infants: baby steps. Acta Paediatr. 2007:96(3):331-2.

15. Liljestrand P, Jeremy J, Wu YW, Ferriero DM, Escobar GJ, Newman TB. Use of the motor performance checklist to study motor outcomes in 5-year-olds. J Paediatr Child Health. 2007; [Epub ahead of print]

16. Wuang YP, Su CY. Reliability and responsiveness of the Bruininks-oserestsky test of motor proficiency- second edition in children with intellectual disability. Res Dev Disabil. 2009;30(5):847-55

17. Goyen T, Duff S. Discriminant validity of the developmental test of visual-motor integration in relation to children with handwriting dysfunction. Aust 0ccup Ther J. 2005; 52(2):109-15.

18. Swinnem SP, Carson RG. The control and learning of patterns of interlimb coordination: past and present issues in normal and disordered control. Acta Psychol (Amst). 2002;110(2-3):129-37.

19. Cavallari P, Cerri G, Baldissera F. Coordination of coupled hand and foot movements during childhood. Exp Brain Res. 2001;141(3):398-409.

20. Fagard J, Hardy-Leger I, Kervella C, Marks A. Changes in the interhemispheric transfer rate and the development of bimanual coordination. J Exp Child Psychol. 2001;80(1):1-22.

21. Gabbard CP. Lifelong motor development. $5^{\mathrm{a}}$ ed. San Francisco: Pearson; 2008.

22. Bobbio TG, Morcillo AM, Barros Filho Ade A, Gonçalves VM. Factors associated with inadequate fine motor skills in Brazilian students of different socioeconomic status. Percept Mot Skills. 2007;105(3 Pt 2):1187-95. 